\title{
Interdisciplinary Evaluation of Intersection Performances-A Microsimulation-Based MCDA
}

\author{
Kadir Diler Alemdar ${ }^{1}$, Ahmet Tortum ${ }^{2}$, Ömer Kaya ${ }^{1, *}$ and Ahmet Atalay ${ }^{2}$ \\ 1 Department of Civil Engineering, Faculty of Engineering and Architecture, Erzurum Technical University, \\ 25100 Erzurum, Turkey; kadir.alemdar@erzurum.edu.tr \\ 2 Department of Civil Engineering, Faculty of Engineering, Atatürk University, 25100 Erzurum, Turkey; \\ atortum@atauni.edu.tr (A.T.); ahatalay@atauni.edu.tr (A.A.) \\ * Correspondence: omer.kaya@erzurum.edu.tr
}

Citation: Alemdar, K.D.; Tortum, A.; Kaya, Ö.; Atalay, A. Interdisciplinary Evaluation of Intersection Performances-A MicrosimulationBased MCDA. Sustainability 2021, 13, 1859. https://doi.org/10.3390/ su13041859

Academic Editor: Juneyoung Park

Received: 6 January 2021

Accepted: 29 January 2021

Published: 9 February 2021

Publisher's Note: MDPI stays neutral with regard to jurisdictional claims in published maps and institutional affiliations.

Copyright: (c) 2021 by the authors. Licensee MDPI, Basel, Switzerland. This article is an open access article distributed under the terms and conditions of the Creative Commons Attribution (CC BY) license (https:/ / creativecommons.org/licenses/by/ $4.0 /)$.

\begin{abstract}
Intersections are the most important regions in terms of urban traffic management. The intersection areas on the corridor should be analyzed together for consistency in traffic engineering. To do so, three intersections on the Vatan Street corridor in İstanbul, the most crowded city of Turkey, were examined. Various geometric and signal designs were performed for intersections and the most suitable corridor design was analyzed. The corridor designs were modeled with the PTV VISSIM microsimulation software. The most suitable corridor design was evaluated by using the results obtained from the microsimulation via analytical hierarchy process (AHP) and technique for order preference by similarity to ideal solution (TOPSIS) from multi criteria decision analysis (MCDA) methods. The evaluation criteria in the study are vehicle delay, queue length, stopped delay, stops, travel time, vehicle safety, CO emission, fuel consumption, and construction cost. As a result, the current and the most suitable alternative corridors were compared according to the comparison parameters and up to $80 \%$ improvements were observed. Thus, some advantages were obtained in terms of energy, environment, time, and cost.
\end{abstract}

Keywords: corridor design; intersection; multi criteria decision making; microsimulation; traffic

\section{Introduction}

In recent years, with the increase in population density and mobility, there has been a significant increase in the number of vehicles in traffic. Therefore, traffic accidents and low speed in traffic flow occurs and causes problems such as congestion and delay. These problems are mostly seen in intersection areas. According to Turkish Statistical Institute (TSI) and Ministry of Interior data, a total of 1,168,144 traffic accidents occurred in Turkey in 2019 [1,2]. In total, $25 \%$ of these accidents occur outside of the settlement and $75 \%$ occur in the settlement. The ratio of accidents occurring only at intersections has a large share with $22 \%$. For this reason, the intersections are the areas that need to be first addressed to produce solutions to urban traffic problems. Intersections must to be of high capacity and security. To meet this requirement, intersections must be designed to be extremely convenient and in accordance with standards. Intersections are divided into two as at-grade and grade separated intersections. They are also divided into signalize and nonsignalized intersections. Both geometric conditions and signaling control types should be considered when designing intersections.

Major traffic problems occur at intersections due to incorrect design combinations. The four main principles must be taken into consideration while designing intersections. These are traffic safety, adequate and high capacity, economic, environmental compatibility [3]. The design of intersections/corridors involves many factors that should be considered comprehensively. Thus, it is a big challenge that should be faced by the local government, transportation engineers, road users (drivers, pedestrians, bicyclists etc.). The design and improvement of intersection/corridor areas will provide great relaxation. It is possible to 
ensure the real effect by applying suitable intersection/corridor designs to a case area. The correct intersection/corridor designs provide significant improvements in the parameters such as vehicle delay, queue length, travel time, emission values, and fuel consumption.

In this study, alternative corridors were designed by using various intersection geometric designs and different signaling systems to solve traffic congestion problems such as vehicle delay, queuing and stops, long travel time. The aim of the study is to provide traffic improvements by obtaining the most suitable corridor designs. To do so, a three-step approach was developed and applied. Firstly, PTV VISSIM microsimulation was preferred to create corridor designs. Secondly, nine criteria were determined for the evaluation of corridor designs. Analytical hierarchy process (AHP) from multi criteria decision analysis (MCDA) methods was applied for the weighting of the criteria. Finally, technique for order preference by similarity to ideal solution (TOPSIS) method was used to analyze the performance of alternative corridors designs. Sensitivity analysis was performed to examine the consistency of the results.

The paper is organized into five sections following this introductory section. The next section provides literature studies on microsimulation-based MCDA and the contribution of this study to the topic, while Section 3 presents brief materials information about the study. Section 4 provides information on microsimulation, AHP, and TOPSIS, respectively. In the Section 5, analysis information of the microsimulation-based MCDM approach is provided by conducting a case study area. Finally, the last section provides a summary and suggestions for future studies.

\section{Literature Review}

Since the design of intersection/corridor is a public problem, researchers have investigated the issue. Researchers have used various microsimulations, algorithms and decision-making methods. In this section, first of all, studies on intersection-corridor and transportation problems which used MCDA and/or microsimulation are examined.

Mandavilli et al. examined and compared the effects of conventional intersection types and modern roundabouts on the environment. For this, six areas where conventional intersection types with different traffic densities exist were determined. The designs were made in SIDRA microsimulation by using traffic data in these regions. As a result, $32 \%$ improvement in $\mathrm{CO}$ emission, 38\% improvement in $\mathrm{CO}^{2}$ emission, 34\% improvement in NOx emission, and $42 \%$ improvement in HC emission were observed [4]. Kwak et al. examined along the corridor the effect of traffic signal optimization on fuel consumption and emissions. TRANSIMS, VT-Micro, and genetic algorithm were used for optimization [5].

Sun et al. compared the VISSIM and CORSIM. Software availability, average control delay, average queue length, and cross-sectional traffic volume were considered as evaluation parameters. They presented program advantages, disadvantages, and differences as a literature study [6]. Golbabaei et al. studied the effects of speed deviation examined in terms of performance measurements and the number of lane-change maneuvers using the AIMSUN. According to the simulation results, the number of lane changes decreased by decreasing speed deviation [7]. Boski et al. studied the effects of vehicle compositions and signal green interval on emissions. VISSIM and En ViVer programs were used for emission estimation. As a result of the study, it was found that it is possible to reduce emissions by changing the signal green interval with vehicle compositions [8].

Dimitrov et al. tried to determine the effects of bus services on traffic by using VISSIMAIMSUN. As a result of the study, it was seen that improvements of number of severely congested road links and total delay parameters could be improved [9]. Bayrak and Abret performed a performance review by creating three different scenarios for four intersections on a corridor. Intersections are designed with VISSIM. AHP was used to weight the criteria considered for intersection design. As a result, the scenarios were compared [10]. The readers can find other studies relation to MCDA and/or VISSIM in [11-19].

In addition, AHP is frequently used in fundamental civil engineering issues. Kaya and Kahraman analyzed the performance of intelligent buildings using MCDA techniques. 
AHP and TOPSIS were used in the study conducted in a fuzzy environment. Three different alternatives for a business center in Istanbul were evaluated and ranked [20]. The mechanical, environmental and economic aspects of recycled aggregate concrete (RAC) were explored to evaluate the most sustainable concrete. In total, 25 mixtures were prepared using RAC at various mass ratios. For the selection of the sustainability of the RAC, a framework based on AHP and TOPSIS, with target compressive strength being the main objective, was used [21].

When the number of vehicles, land use and mobility in Turkey are examined, it is observed that the performance of the current intersection designs is insufficient. It is clear that this situation will create various disadvantages in the current traffic conditions. In this study, intersection-based corridor designs were made in the most central area of İstanbul. Accordingly, three methods were used for the first time in the literature. It is thought that with these methods, more realistic results will be obtained in the solution of corridor design problems.

There are some shortcomings in previous studies and these are (i) vehicle inputs for microsimulation were made in passenger car units, not in vehicle composition type. (ii) The designs were based on intersections, not corridors. This situation causes to retain small scale of the traffic flow analysis. (iii) The combinations of alternative geometric statuses of the designed intersections were limited. (iv) The number of scenarios created was insufficient while the most suitable intersection/corridor design analysis was performed. (v) No ranking method was used in the selection or rank of alternative scenarios.

Although there are many studies which apply microsimulation approach on suitable corridor design problems as mentioned above, there is still a gap on selection of suitable corridor design. We solved this gap by using a VISSIM-based MCDA. The study presents various contributions to the literature in some ways: (i) vehicle inputs for microsimulation were made in vehicle composition type. This provides a more realistic design. (ii) This is the first time that such a high number of scenarios were created for corridor designs. (iii) In this study, traffic flow analysis was examined based on corridor. (iv) Combinations of all conventional intersection types were made, and alternative intersection types were produced accordingly. (v) In the process of determining the most suitable corridor design, ranking method was used for the first time. (vi) VISSIM-based AHP and TOPSIS approaches were proposed. These methods were used together for the first time in corridor-intersection designs in this study.

\section{Materials}

Intersection areas are the points where traffic mobility and accidents in the city are the highest. In particular, conventional intersection designs have a lot of disadvantages. Excessive vehicle delay, queue length, travel time, emission values, and fuel consumption are examples of these disadvantages. To this end, corridor-based intersection designs were examined in order to minimize the negative effects of intersection performances in this study. The framework of the paper is given in Figure 1. First of all, traffic data to be used for corridor design was obtained and VISSIM modeling was performed with these data. In total, 30 different corridors were obtained and calibration was performed to test the consistency of the microsimulation results. As a result of the calibration process, it was observed that 18 corridor designs were usable for analysis. Various geometric and signalization designs were performed for corridors. Conventional intersection types were used for geometric designs. Webster and VISSIM Signal Optimization method were preferred for signalization designs. After this stage, nine criteria were determined via literature, expert and author opinions. The weighting of the criteria was determined by four academicians and five experts in the field of transportation. Performance analysis of the most suitable corridor designs was performed by using the results obtained from the microsimulation and TOPSIS. 


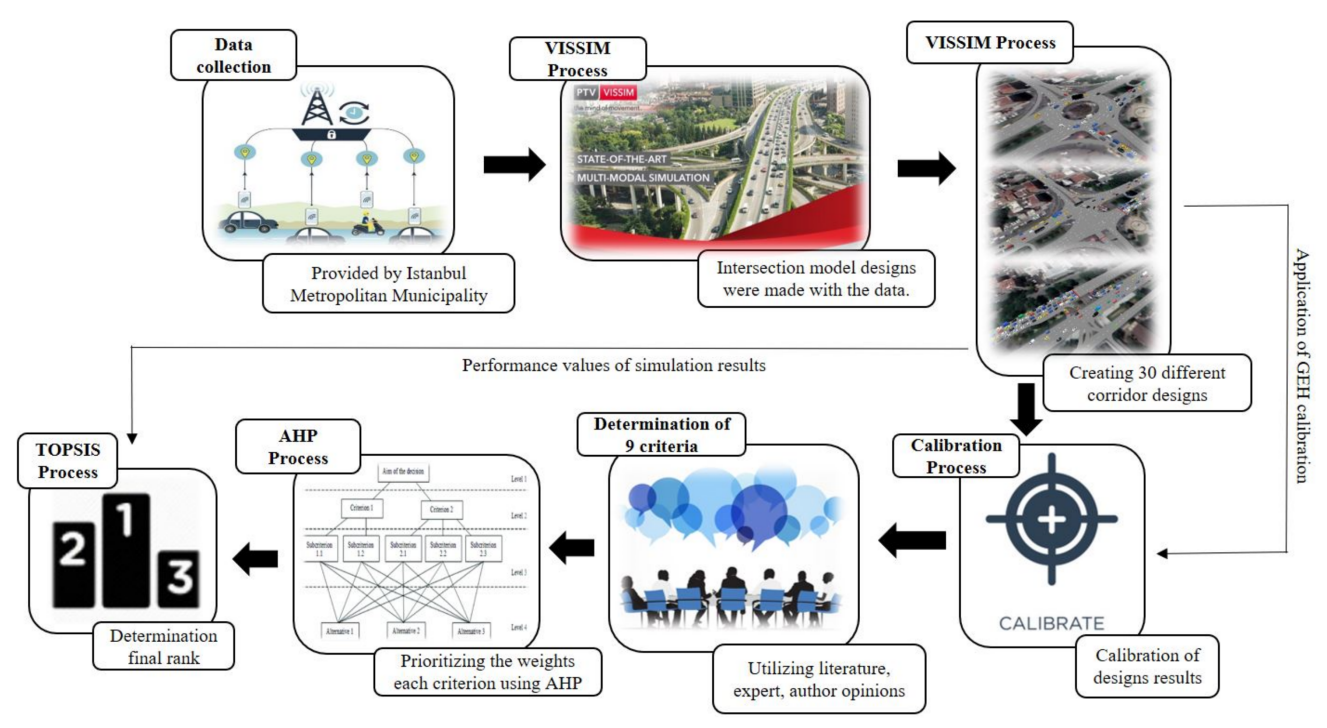

Figure 1. Framework of the study.

\subsection{Study Area}

Istanbul is Turkey's most populous city with a population of 16 million. As of the end of 2019, there are more than about four million motor vehicles in Istanbul [1]. Traffic mobility in the city is over acceptable limits. The high number of vehicles and high mobility creates many important traffic problems. Many problems occur such as traffic congestion, delay, increase in fuel consumption due to the traffic density at intersection points.

Vatan Street is the center of Istanbul's most important public and social areas (universities, Istanbul Metropolitan Municipality, hospital, government buildings, etc.). The street is one of the regions where the urban traffic population is the most intense because of the high demand for transportation. For these reasons, Vatan Street corridor was chosen as the study area for Istanbul. The corridor length is $2580 \mathrm{~m}$ and there are three at grade intersections on the corridor. The study area and traffic flows are presented in Figure 2.

\subsection{Evaluation Criteria}

In order to measure the performance of the corridor designs, evaluation criteria should be determined. The literature, author and expert opinions were used to determine the evaluation criteria for this study. The definition of the evaluation criteria for the intersection/corridor design and their usage in the literature are given in Table 1. The criteria used in the literature were taken into account in the study. Additionally, other criteria were added considering the opinions of the authors and experts.

\subsection{Data Collection}

The collection and evaluation of traffic volume data is an important issue for traffic control, audit and management. The traffic flows of the intersections on the corridor are presented in Figure 2. In order to determine the traffic flow values in the study area, the traffic counts were conducted. The count results were obtained as a result of $15 \mathrm{~min}$ measurements at 07:00-09:00 a.m. and 04:30-06:30 p.m. Vehicle types were evaluated separately and accordingly counts were made. Comparing the morning and evening counts, traffic volume in the morning was preferred in the study because the traffic volume in the morning was higher. The traffic counts used in the study are given in Table 2. 


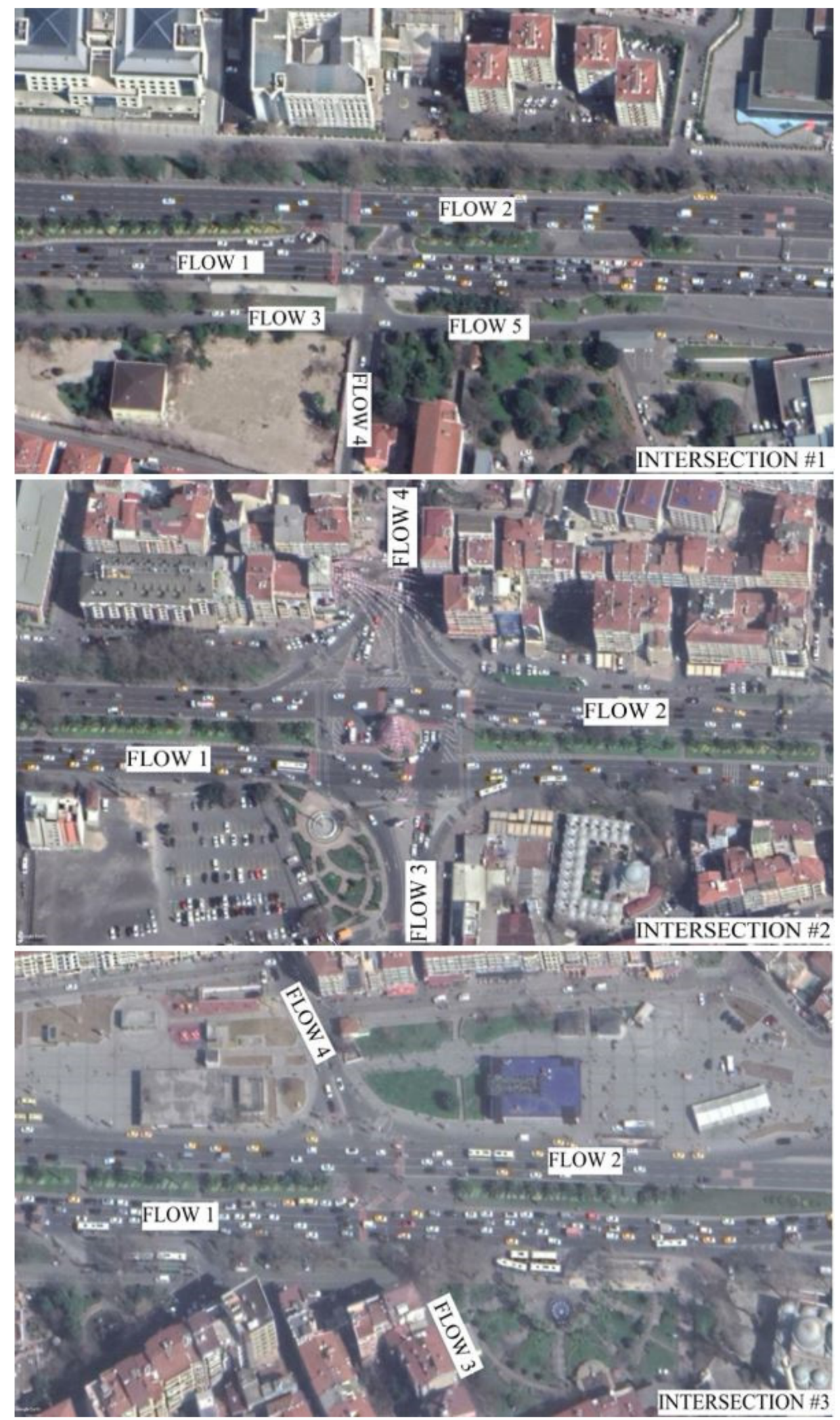

Figure 2. Study area and traffic flows on intersections. 
Table 1. Definition and literature search of evaluation criteria.

\begin{tabular}{|c|c|c|c|c|c|c|c|c|c|}
\hline Criteria & Definition & (1) & (2) & (3) & (4) & (5) & (6) & (7) & (8) \\
\hline C.1-Vehicle Delay & $\begin{array}{l}\text { One of the most important performance indicators used in the evaluation of } \\
\text { intersection/corridor design. }\end{array}$ & $\boldsymbol{\nabla}$ & $\boldsymbol{\nabla}$ & $\boldsymbol{\nabla}$ & $\boldsymbol{\nabla}$ & & & & $\boldsymbol{\nabla}$ \\
\hline C.2-Queue Length & $\begin{array}{l}\text { It is one of the indicators that best shows the operation quality and condition of } \\
\text { the intersection/corridor. }\end{array}$ & $\boldsymbol{\nabla}$ & $\boldsymbol{\nabla}$ & & & & & $\boldsymbol{\nabla}$ & $\boldsymbol{\nabla}$ \\
\hline C.3-Stopped Delay & $\begin{array}{c}\text { It is the delay for the vehicle that occurs when the vehicles are at rest } \\
\text { during traffic. }\end{array}$ & & & & & & & $\nabla$ & $\boldsymbol{\nabla}$ \\
\hline C.4-Stops & $\begin{array}{l}\text { It is the forced immobility of the vehicles due to traffic congestion } \\
\text { and signalization. }\end{array}$ & & $\boldsymbol{\nabla}$ & & $\boldsymbol{\nabla}$ & & & & $\boldsymbol{\nabla}$ \\
\hline C.6-Vehicle Safety & $\begin{array}{l}\text { Vehicle safety is a parameter to be taken into account in } \\
\text { intersection/corridor designs. }\end{array}$ & & & & & & $\boldsymbol{\nabla}$ & $\boldsymbol{\nabla}$ & $\boldsymbol{\nabla}$ \\
\hline C.7-CO Emission & $\begin{array}{l}\text { It is known that vehicles emit more emissions at low speeds and at rest. It is one } \\
\text { of the parameters to be taken into account in intersection/corridor designs due to } \\
\text { environmental concerns. }\end{array}$ & & & & $\boldsymbol{\nabla}$ & $\boldsymbol{\nabla}$ & & & $\boldsymbol{\nabla}$ \\
\hline C.8-Fuel Consumption & $\begin{array}{l}\text { The vehicle's stop-and-go and low speeds increase the consumption of fuel, } \\
\text { which is a nonrenewable resource. It should be taken into consideration in } \\
\text { designs to reduce fuel consumption. }\end{array}$ & & & & $\boldsymbol{\nabla}$ & $\boldsymbol{\nabla}$ & & $\nabla$ & $\boldsymbol{\nabla}$ \\
\hline
\end{tabular}

Sources: (1) Comert [22]; (2) Yao et al. [23]; (3) Zheng et al. [24]; (4) Stevanovic et al. [25]; (5) Huang et al. [26]; (6) Stevanovic et al. [27]; (7) Alemdar et al. [28]; (8) proposed paper. 
Table 2. Traffic counts of intersections.

\begin{tabular}{cccc}
\hline & \multicolumn{3}{c}{ Traffic Flow Data (veh/h) } \\
\hline Vehicle Type & Intersection \#1 & Intersection \#2 & Intersection \#3 \\
\hline Car & 3207 & 4138 & 770 \\
Van & 461 & 352 & 147 \\
Taxi & 298 & 583 & 270 \\
Taxi Minibus & 94 & 117 & 63 \\
Service Minibus & 199 & 329 & 97 \\
Public Transport & 72 & 139 & 72 \\
Heavy Truck & 13 & 19 & 7 \\
\hline
\end{tabular}

\section{Methods}

The evaluation of intersection/corridor analysis in the literature is generally performed using microsimulation programs. There are many evaluation criteria that affect the traffic flow in the intersection/corridor. Therefore, a multi criteria decision making problem needs to be solved. In this study, intersection/corridor designs were performed by using PTV VISSIM. Nine criteria were taken into account for the evaluation of intersections/corridors and AHP method was preferred for weighting the criteria. In order to evaluate the performance of intersection/corridor designs, the ranking process was done by TOPSIS method. Finally, the corridor design that had the best performance value was determined.

\subsection{Microsimulation}

Traffic simulation programs are widely used to solve urban traffic congestion and planning problems. Microsimulation is preferred for modeling heterogeneous traffic [29]. Microsimulation is frequently used because it is safer, cheaper, and faster than field studies [30].

PTV VISSIM is one of the most used microsimulation programs [31,32]. In this study, VISSIM program was used to design the geometric status and signaling systems of intersections on the corridor. The usability of VISSIM has been proven by literature studies. VISSIM has been developed for traffic modeling and evaluation of urban transportation systems and transit transportation systems; is a behavior based microsimulation program. Various road combinations, traffic signaling systems and public transportation systems are designed for urban road traffic via this simulation program.

It is seen that VISSIM has many advantages in various fields compared to other microsimulation programs. VISSIM is a program that has a wide geometric design infrastructure, modeling all transit modes in traffic, random routes, and vehicle production [33]. VISSIM is more understandable in terms of user interface and easier to implement [34].

\subsection{Analytical Hierarchy Process (AHP)}

AHP is one of the MCDA methods developed by Thomas L. Saaty in 1977 to solve complex problems [35]. This method is the most commonly used method for solving problems in economic, political, social, and technical fields [36-38]. AHP is a structure in which multiple decision makers are involved in the decision-making process. AHP is a decision making method that includes the opinions, preferences and experiences of individuals and groups [39]. As with all decision-making processes, the all factors that affect result need to be identified. Considering that these factors affect each other, the ratio of the elements affecting each other is determined through binary comparison. The hierarchical structure of AHP consists of at least three levels [40]. First, the purpose of the study should be determined. At the second level, there are evaluation criteria that affect the study and at the last level, there are alternatives. The AHP method consists of six process steps, as follows [41,42]:

Step 1. Defining the problem and determining evaluation criteria;

Step 2. Constructing of AHP hierarchy;

Step 3. Making pairwise comparison matrix. 
Pairwise comparison matrices are established to compare the advantages of the criteria in the hierarchical structure of AHP with each other. In the pairwise comparison matrix, the relative importance of $i$. and $j$. criteria is determined according to the higher level factor. If there are $n$ elements in the comparison matrix, $n *(n-1) / 2$ comparisons are required. The Saaty scale is used in the pairwise comparison matrices [43]. Comparisons are made for elements that remained above the diagonal, such that all values of the pairwise comparison matrix are one.

Step 4. The normalization of the pairwise comparison matrices is made by Equation (1).

$$
a \prime_{i j}=\frac{a_{i j}}{\sum_{i=1}^{n} a_{i j}}
$$

Step 5. The priority vectors are calculated by using Equation (2).

$$
w_{i}=\left(\frac{1}{n}\right) \sum_{j=1}^{n} a_{i j}^{\prime} i, j=1,2, \ldots, n
$$

Step 6. Calculation of consistency ratio (CR): $C R$ is calculated by Equations (3) and (4) in AHP method.

$$
\begin{gathered}
C R=\frac{C I}{R I} \\
C I=\lambda_{\text {max }}-\frac{n}{n-1}
\end{gathered}
$$

where; $a_{i j}$ : decision alternatives, $\lambda_{\text {max }}$ : eigenvalue, $C I=$ consistency index.

The random index (RI) value is calculated for cases where the number of evaluation criteria is up to 15 . RI values are presented in [28]. If the $C R$ is less than 0.10 , the comparison matrix is consistent. Otherwise, the matrix is inconsistent and the AHP processing steps need to be reviewed again.

\subsection{Technique for Order Preference by Similarity to Ideal Solution (TOPSIS)}

TOPSIS is a method developed by Hwang and Yoon in 1980 and has many applications. This method is based on two fundamental points. The positive ideal solution (PIS) and the negative ideal solution (NIS) are expressed as these points. In the TOPSIS method, alternatives that are closest to PIS and at the farthest distance from NIS are defined as the best decision alternatives [44]. The TOPSIS method consists of six process steps, as follows [45]:

Step 1. The decision matrix is established by Equation (5).

$$
R_{i j}=\left[\begin{array}{cccc}
r_{11} & r_{12} & \ldots & r_{1 n} \\
r_{21} & r_{22} & \ldots & r_{2 n} \\
\vdots & \vdots & \ldots & \vdots \\
r_{i 1} & r_{i 2} & \ldots & r_{i n} \\
\vdots & \vdots & \ldots & \vdots \\
r_{m 1} & r_{m 2} & \ldots & r_{m n}
\end{array}\right]
$$

where $r_{i j}$ is the value of the $j$ th attribute in the $i$ th alternative; $i=1,2, \ldots m ; j=1,2, \ldots, n$.

Step 2. Formation of normalized decision matrix.

Normalization is undertaken using different methods in the literature. There are different approaches such as vector, linear and nonmonotonous normalization. In this study, vector normalization is undertaken by using Equation (6).

$$
r^{\prime}{ }_{i j}=\frac{r_{i j}}{\sqrt{\sum_{i=1}^{m} r_{i j}^{2}}}
$$


Step 3. Calculate the weighted normalized decision matrix.

The weights $\left(w_{j}\right)$ of the criteria were determined by various criteria weighting methods. The weighted normalized decision matrix is calculated by Equation (7).

$$
v_{i j}=w_{j} * r_{i j}^{\prime}
$$

Step 4. Determine the positive ideal solution $A^{+}$and the negative ideal solution $A^{-}$

$$
\begin{aligned}
& A^{+}=\left\{\left(\max _{i} v_{i j} \mid j \in J\right),\left(\min _{i} v_{i j} \mid j \in J \prime\right) \mid i=1,2, \ldots, m\right\}=\left\{v_{1}^{+}, v_{2}^{+}, \ldots, v_{n}^{+}\right\} \\
& A^{-}=\left\{\left(\min _{i} v_{i j} \mid j \in J\right),\left(\max _{i} v_{i j} \mid j \in J \prime\right) \mid i=1,2, \ldots, m\right\}=\left\{v_{1}^{-}, v_{2}^{-}, \ldots, v_{n}^{-}\right\}
\end{aligned}
$$

If the evaluation criteria are in terms of benefit; $A^{+}$is the best value of $v ; A^{-}$consists of the worst values. If the evaluation criteria are in terms of cost; $A^{-}$is the best value of $v$; $A^{+}$consists of the worst values.

Step 5. Calculation of discrimination criteria.

For each decision option in TOPSIS, there are two measures of separation, called the positive ideal distinction $S_{i}^{+}$and the negative ideal distinction $S_{i}^{-}$. The Euclidean distance approach is used to calculate the separation criteria.

$$
\begin{aligned}
& S_{i}^{+}=\sqrt{\sum_{j=1}^{n}\left(v_{i j}-v_{j}^{+}\right)^{2}} \\
& S_{i}^{-}=\sqrt{\sum_{j=1}^{n}\left(v_{i j}-v_{j}^{-}\right)^{2}}
\end{aligned}
$$

Step 6. Calculate the relative closeness $(R C)$ of each alternative by the Equation (12).

$$
R C_{i}=\frac{S_{i}^{-}}{S_{i}^{-}+S_{i}^{+}}
$$

The value of $R C$ reflects the relative superiority of the alternatives. Larger $R C$ indicates that the alternative $i$ is relatively better, whereas smaller $R C$ indicates this alternative is relatively poorer [45].

\section{Result and Discussion}

\subsection{Design of Microsimulation Model}

Firstly, the geometric situation of the study area was considered and a simulation of the current situation of the study area was performed by VISSIM. Road networks were designed for the current situation and alternatives. After this stage, vehicle assignment was made according to the traffic volume values and vehicle compositions. Vehicle assignments were based on the type of vehicle. A total of 205 different vehicle route assignments were made in order to transfer the movements of the vehicles in the traffic flow to the simulation in a realistic way. Then, priority rules were performed in conflict areas to prevent vehicle conflict occurring at intersections and road connection areas. Signal systems were designed to control traffic flow. At this stage, Webster Signal Optimization method was applied for intersection 3 considering traffic volume values and for other intersections, VISSIM Signal Optimization was used.

Current and alternative corridors designs were simulated separately for each design. All designs were analyzed and debugged. After this stage, measurement toolboxes were used in order to obtain microsimulation results. A total of 30 alternative corridor designs were performed by VISSIM both in terms of geometric design and signal systems. Consistency analysis was performed for all designs by GEH calibration method for traffic volume. 
As a result, 18 out of 30 corridor designs were found to be usable. The corridor designs are presented in Table 3.

Table 3. Corridor designs.

\begin{tabular}{|c|c|c|c|c|c|c|}
\hline \multirow{3}{*}{ Alternative } & \multicolumn{3}{|c|}{ Corridor Design Geometric Status } & \multicolumn{3}{|c|}{ Corridor Design Signal Status } \\
\hline & \multicolumn{6}{|c|}{ Intersection No } \\
\hline & $\# 1$ & \#2 & $\# 3$ & $\# 1$ & \#2 & \#3 \\
\hline 1 & CS & CS & CS & CS & CS & CS \\
\hline 2 & GS & AGC & CS & CS & CS & Webster \\
\hline 3 & GS & GS & CS & CS & CS & Webster \\
\hline 4 & GS & CS & CS & CS & CS & CS \\
\hline 5 & CS & AGC & CS & VISSIM & CS & CS \\
\hline 6 & CS & AGC & CS & VISSIM & CS & Webster \\
\hline 7 & CS & GS & CS & VISSIM & CS & Webster \\
\hline 8 & CS & Roundabout & CS & VISSIM & CS & Webster \\
\hline 9 & CS & CS & CS & VISSIM & CS & CS \\
\hline 10 & CS & AGC & CS & VISSIM & CS & Webster \\
\hline 11 & CS & CS & CS & CS & CS & Webster \\
\hline 12 & CS & Roundabout & CS & CS & CS & Webster \\
\hline 13 & CS & CS & CS & VISSIM & CS & Webster \\
\hline 14 & CS & AGC & CS & VISSIM & CS & CS \\
\hline 15 & GS & AGC & CS & CS & CS & CS \\
\hline 16 & CS & GS & CS & VISSIM & CS & CS \\
\hline 17 & GS & GS & CS & CS & CS & CS \\
\hline 18 & GS & CS & CS & CS & CS & Webster \\
\hline
\end{tabular}

Note: CS: current status, GS: grade separated, AGC: at grade channelized.

All types of intersections of grade separated were designed as underpass intersections. Seven different geometric status used in corridor design are given in Figure 3.

As is clear from Figure 3, two different geometric designs were made for the intersection 1. For intersection 1, 1.1 represents the current status, 1.2 represents the grade separated status. For intersection 2, 2.1 represents the current status, 2.2 represents the grade separated status, 2.3 represents the roundabout status, 2.4 represents the at grade status. Since no different geometric design was made for intersection 3, 3.1 represents the current situation. In the Figure 3, the grade separated design was made for only intersections 1 and 2. This is because when the standards are examined, it is seen that traffic volume data of intersection 3 is not sufficient for grade separated status [46].

Six different signal status were used for the corridor designs and these statuses include studies on signal periods. Webster Signal Optimization was used only at intersection 3. When traffic volume values were examined, only intersection 3 was suitable for Webster Signal Optimization. Saturation flow in Webster Signal Optimization took 1894 passenger cars unit per hour per lane. For other intersections, the Signal Optimization toolbox at VISSIM was preferred.

\subsection{Results of VISSIM}

Performance values were obtained from microsimulation by considering evaluation criteria. These performance values are given in Table 4. For performance values (C.9Construction Cost) that cannot be obtained from VISSIM, expert and authors opinions were used. 

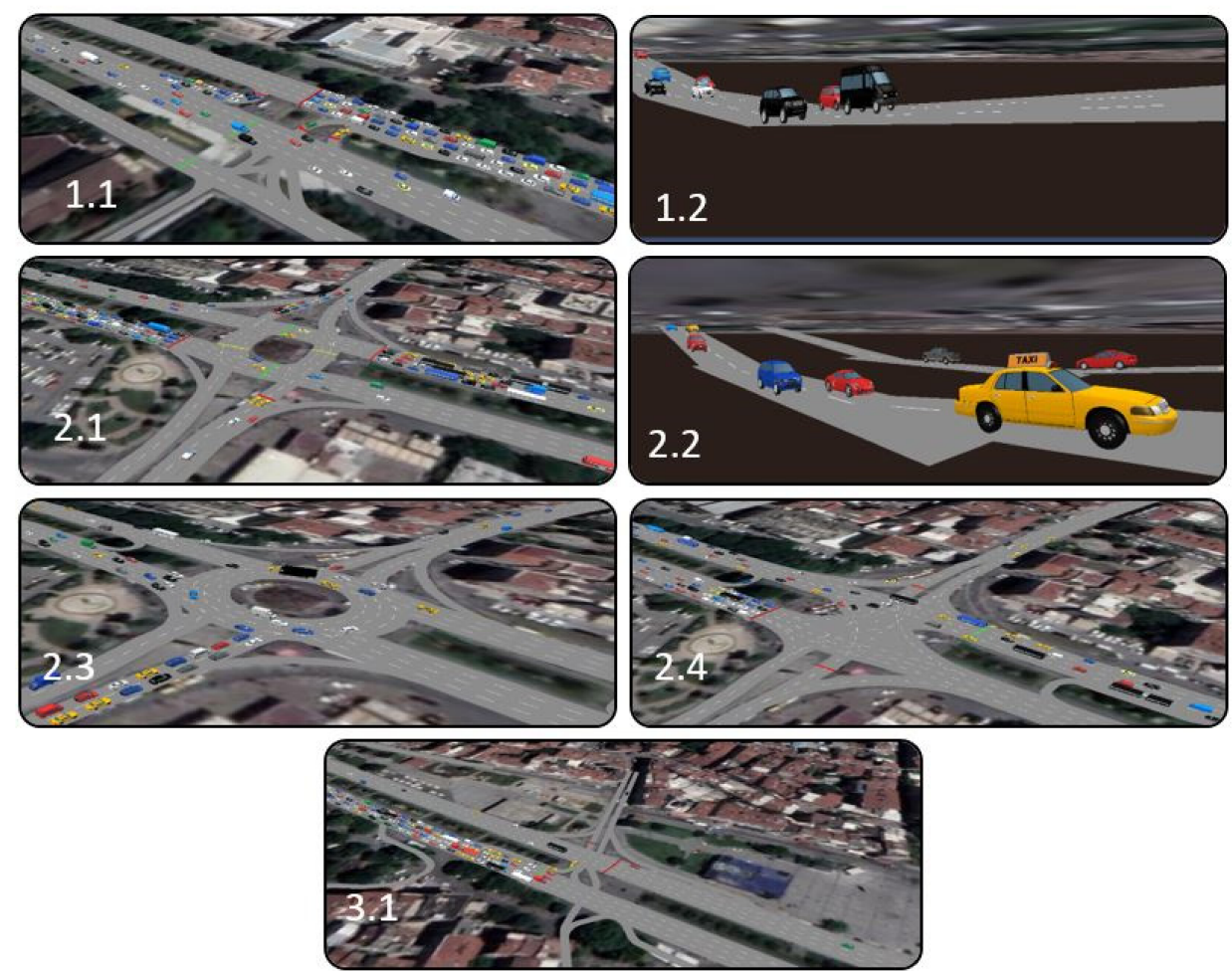

Figure 3. Geometric status of intersections.

Table 4. Performance values of corridor designs.

\begin{tabular}{cccccccccc}
\hline Alternative & $\begin{array}{c}\text { Vehicle } \\
\text { Delay } \\
(\mathbf{s n})\end{array}$ & $\begin{array}{c}\text { Queue } \\
\text { Length } \\
\mathbf{( m )}\end{array}$ & $\begin{array}{c}\text { Stopped } \\
\text { Delay } \\
\mathbf{( s n )}\end{array}$ & Stops & $\begin{array}{c}\text { Travel } \\
\text { Time } \mathbf{( s n )}\end{array}$ & $\begin{array}{c}\text { Vehicle } \\
\text { Safety }\end{array}$ & $\begin{array}{c}\text { CO } \\
\text { Emission } \\
\text { (gr) }\end{array}$ & $\begin{array}{c}\text { Fuel Con- } \\
\text { sumption } \\
\text { (lt) }\end{array}$ & $\begin{array}{c}\text { Construction } \\
\text { Cost }\end{array}$ \\
\hline 1 & 176.08 & 166 & 100.24 & 2.62 & 497.78 & 112 & 166.17 & 9.00 & 2.1 \\
2 & 178.67 & 37.7 & 65.79 & 2.94 & 493.51 & 160 & 159.90 & 8.66 & 11 \\
3 & 92.58 & 71.9 & 22.73 & 1.46 & 320.00 & 126 & 95.41 & 5.17 & 20.7 \\
4 & 152.20 & 94.99 & 69.23 & 2.31 & 355.41 & 113 & 144.47 & 7.82 & 11.4 \\
5 & 120.98 & 34.64 & 48.72 & 2.09 & 371.88 & 158 & 142.62 & 7.72 & 1.7 \\
6 & 185.81 & 34.91 & 71.48 & 3.40 & 470.19 & 158 & 169.31 & 9.17 & 1.7 \\
7 & 126.99 & 113.99 & 31.51 & 2.05 & 340.51 & 126 & 142.09 & 7.69 & 11.4 \\
8 & 188.39 & 91.22 & 31.31 & 3.12 & 388.48 & 119 & 151.65 & 8.21 & 1.9 \\
9 & 174.01 & 108.8 & 100.26 & 2.63 & 508.53 & 112 & 165.46 & 8.96 & 2.1 \\
10 & 191.31 & 39.32 & 89.85 & 3.18 & 636.99 & 158 & 179.17 & 9.70 & 1.7 \\
11 & 221.30 & 224.6 & 116.91 & 3.64 & 553.33 & 112 & 181.48 & 9.83 & 2.1 \\
12 & 248.87 & 117.1 & 77.75 & 3.95 & 599.46 & 119 & 177.96 & 9.64 & 1.9 \\
13 & 217.15 & 106.7 & 93.77 & 3.74 & 430.38 & 112 & 171.00 & 9.26 & 2.1 \\
14 & 176.24 & 141.2 & 111.42 & 2.25 & 451.42 & 152 & 153.32 & 8.30 & 1.7 \\
15 & 105.14 & 41.06 & 44.32 & 1.71 & 364.47 & 160 & 130.17 & 7.05 & 11 \\
16 & 38.37 & 14.51 & 13.55 & 0.73 & 234.55 & 126 & 105.80 & 5.73 & 11.4 \\
18 & 17.55 & 5.52 & 6.47 & 0.35 & 208.71 & 125 & 91.82 & 4.97 & 20.7 \\
\hline
\end{tabular}

When Table 4 is examined, it is seen that the performance value of the alternative corridor 17 has the best value in almost all evaluation criteria. However, a multicriteria problem must be solved in order to determine the best corridor alternative. Therefore, the best corridor alternative was determined by using AHP and TOPSIS in this study. 


\subsection{Analysis of Analytical Hierarchy Process}

AHP method was used to calculate the weights of the evaluation criteria. Firstly, a decision-making team was established and pairwise comparison matrices were formed according to the Saaty Scale. The final criterion weighting was obtained by averaging the weights obtained as a result of pairwise comparisons. CR was calculated using Equation (3) to analyze the consistency of pairwise comparison matrices. In this study, CR was calculated as 0.049 . Weighted total vectors and priority vectors were obtained, and the weights of the evaluation criteria were calculated and presented in Table 5. For simplicity, steps of the AHP method were not presented. However, they are available upon request.

Table 5. Weights of evaluation criteria.

\begin{tabular}{cccccccccc}
\hline Criteria & C.1 & C. 2 & C.3 & C.4 & C.5 & C.6 & C.7 & C.8 & C.9 \\
Weight & 0.155 & 0.129 & 0.046 & 0.043 & 0.102 & 0.243 & 0.068 & 0.059 & 0.154 \\
\hline
\end{tabular}

According to the AHP results, it is seen that the most important evaluation criterion is C.6-Vehicle Safety. The least significant evaluation criterion was observed as C.4-Stops. The order of importance of the criteria is C.6-C.1-C.9-C.2-C.5-C.7-C.8-C.3-C.4.

\subsection{Analysis of Technique for Order Preference by Similarity to Ideal Solution}

Performance values of the alternative corridors were obtained with the help of VISSIM and expert opinions. The ranking of the alternatives was done by TOPSIS. First, the benefit/cost aspects of the evaluation criteria were determined. In this study, all evaluation criteria were cost aspects. The decision matrix was established and then normalization process was obtained. After this stage, weighted normalized decision matrices were formed. The PIS and NIS clusters of the evaluation criteria were formed according to the cost aspect of the criteria and are given in Table 6. In addition, calculation steps of TOPSIS method are available upon request.

Table 6. PIS and NIS clusters.

\begin{tabular}{cccccccccc}
\hline & C.1 & C.2 & C.3 & C.4 & C.5 & C.6 & C.7 & C.8 & C.9 \\
\hline$A^{+}$ & 0.004 & 0.002 & 0.001 & 0.001 & 0.011 & 0.048 & 0.010 & 0.008 & 0.006 \\
$A^{-}$ & 0.054 & 0.064 & 0.017 & 0.015 & 0.035 & 0.069 & 0.019 & 0.016 & 0.079 \\
\hline
\end{tabular}

The positive and negative ideal distinction matrices were created by using PIS and NIS cluster. The ranking of the alternative corridors was made according to the distinction criteria. The ranking process was done by ranking from large to small according to $C_{i}^{+}$ parameter. The ranking of alternatives was made according to the performance values and are given in Table 7.

Table 7. Ranking of alternative corridors.

\begin{tabular}{cccccccccc}
\hline Ranking & 1 & 2 & 3 & 4 & 5 & 6 & 7 & 8 & 9 \\
\hline Alternative & 5 & 16 & 6 & 8 & 10 & 9 & 15 & 13 & 14 \\
$C_{i}^{+}$ & 0.738 & 0.705 & 0.656 & 0.644 & 0.628 & 0.616 & 0.608 & 0.588 & 0.570 \\
Ranking & 10 & 11 & 12 & 13 & 14 & 15 & 16 & 17 & 18 \\
\hline Alternative & 1 & 17 & 12 & 2 & 4 & 7 & 11 & 3 & 18 \\
$C_{i}^{+}$ & 0.554 & 0.550 & 0.545 & 0.534 & 0.525 & 0.522 & 0.473 & 0.451 & 0.383 \\
\hline
\end{tabular}

As it clear from Table 7, it is seen that the alternative 5 has the best value according to performance ranking. The worst alternative is the alternative 18. When the best six alternative corridors were examined, it is seen that the signal status of intersection 1 is VISSIM Signal Optimization. When the ranking of the most suitable alternative corridor 
was examined, it is seen that the current geometric and signal system designs of intersection 2 are insufficient and need to be changed. No geometric design was made due to the restriction of traffic volume values of intersection 3 .

The reason for the low performance values of alternative 18 is that intersection 1 is grade separated and intersection 2 is current status. Since the traffic flow speed at intersection 1 is high, intersection 2 cannot meet the traffic volume coming from intersection 1. Intersection 2 is not designed as suitable the traffic flow speed at intersection 1 . The performance values of the current and best corridor design are given in Table 8. While analyzing the corridor designs, the analysis values of the other evaluation criteria except the $\mathrm{C} 9$ evaluation criterion were obtained via the VISSIM program. The analysis value of the C9 criterion was determined with the help of the decision-makers.

Table 8. Performance values of the current and best alternative corridor.

\begin{tabular}{cccccccccc}
\hline $\begin{array}{c}\text { Coridor } \\
\text { Alternative }\end{array}$ & $\begin{array}{c}\text { Vehicle } \\
\text { Delay } \\
(\mathbf{s n})\end{array}$ & $\begin{array}{c}\text { Queue } \\
\text { Length } \\
\mathbf{( m )}\end{array}$ & $\begin{array}{c}\text { Stopped } \\
\text { Delay } \\
\mathbf{( s n )}\end{array}$ & Stops & $\begin{array}{c}\text { Travel } \\
\text { Time (sn) }\end{array}$ & $\begin{array}{c}\text { Vehicle } \\
\text { Safety }\end{array}$ & $\begin{array}{c}\text { CO } \\
\text { Emission } \\
\text { (gr) }\end{array}$ & $\begin{array}{c}\text { Fuel Con- } \\
\text { sumption } \\
\text { (lt) }\end{array}$ & $\begin{array}{c}\text { Construction } \\
\text { Cost }\end{array}$ \\
\hline 1 & 176.08 & 165.98 & 100.24 & 2.62 & 497.775 & 112 & 166.17 & 9.00 & 2.1 \\
5 & 120.98 & 34.64 & 48.72 & 2.09 & 371.875 & 158 & 142.62 & 7.72 & 1.7 \\
$\%$ & 44.79 & 79.13 & 72.75 & 31.83 & 25.29 & -41.07 & 12.01 & 12.01 & 19.05 \\
\hline
\end{tabular}

Note: \% means that percent of improvement of corridor performance values.

When the corridor designs 1 and 5 were handled, it was observed that all the criteria except vehicle safety criterion were improved. When the improvement rates were examined, it is seen that it is possible to make an improvement of approximately $80 \%$.

\subsection{Sensitivity Analysis}

The evaluation criteria significantly affect the accuracy of the study. For this reason, effectiveness analysis should be done on the criteria. Therefore, various scenarios were established for the sensitivity analysis of the criteria and the analysis was carried out. The scenarios were created by changing the weights of criteria and their effects on the most suitable corridor result were examined. The scenarios are as follows.

- Scenario 1, the current version of criteria weights is considered;

- Scenario 2, all criteria weights are equal;

- Scenario 3, the weight of the C.1, C.2 and C.3 criteria is decreased by $50 \%$;

- Scenario 4, the weight of the C.4, C.5 and C.6 criteria is decreased by 50\%;

- Scenario 5, the weight of the C.7, C.8 and C.9 criteria is decreased by $50 \%$;

- Scenario 6, the weight of the first three criteria (C.6, C.1 and C.9), which currently have the highest weight of the nine criteria, is decreased by $25 \%$.

Sensitivity analysis was performed for TOPSIS considering the criteria weights in the scenarios. The sensitivity graph obtained according to the results of the analysis is given in Figure 4.

It was observed that the results are sensitive in Figure 4. Thus, it is seen that the effects of the evaluation criteria are independent variables. The total of criteria weights for all scenarios is 1 . In the sensitivity analysis, it was observed that the ranking of alternative corridors design changes according to the scenarios. The analysis shows that the criteria are acceptable.

In this study, Vatan street corridor, which is one of the densest regions of Istanbul (reflects Turkey as a whole), was chosen as the study area. The most suitable alternative corridor designs to be obtained by the design of the intersections on this corridor were determined by microsimulation and MCDA methods. 


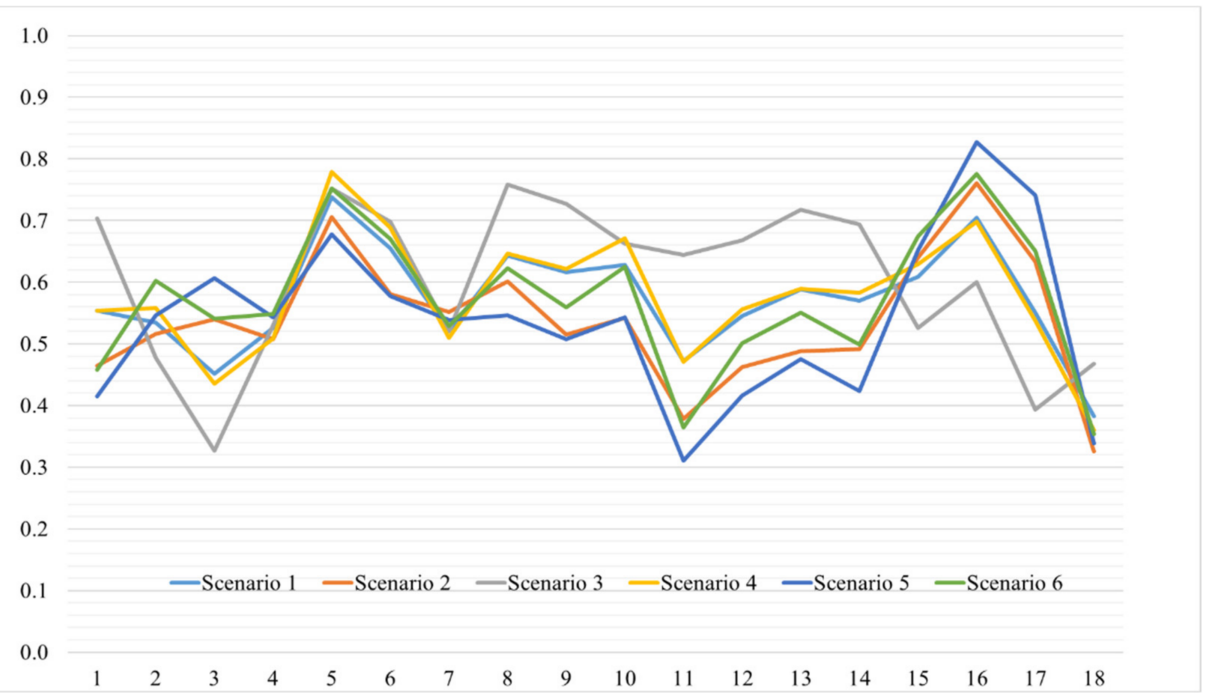

Figure 4. Sensitivity analysis graph.

Since corridor design selection is a multicriteria problem, it is not sufficient to evaluate alternatives by only VISSIM. Therefore, AHP and TOPSIS were used in this study to determine the most suitable alternative corridor. AHP was preferred because it is an accepted method for weighting criteria. TOPSIS was preferred because of its advantages such as ease of use, easy interpretation and easy to understand results.

The current geometric and signal status in the corridor was observed to be problematic. Therefore, Webster and VISSIM Signal Optimization were applied to intersections signal systems and VISSIM microsimulation was used for geometric design of intersections. Strategic and scientific solutions were presented for the problems in the current corridor with proposed methodology. As a result of the proposed methodology, significant improvements were achieved in terms of traffic parameters between the most suitable and the current corridor design. By analyzing all intersection/corridor designs in the city with a scientific framework, it is possible to obtain a more sustainable transportation and city model in terms of both environmental and energy. In addition, the study can be expressed as a guideline for the big challenge facing local governments, so that the concept of sustainable transportation reaches the wider community.

In this study, there are limitations that need to be discussed. When the data collection period in the study is examined, the counts were made in January, one of the lowest months in terms of traffic density. A more effective study can be obtained by considering the annual average traffic counts. Driver behavior models used in microsimulation models limit the accuracy of the study. VISSIM driver behavior patterns are not the same as real driver behavior models, as they reflect German drivers. In simulation models, vehicle assignment and route assignment are generally made in terms of passenger car unit. Considering that this situation does not reflect the actual traffic conditions, the assignments were made according to the vehicle types in this study. To increase of depth of the study, the most suitable corridor selection can be made more effectively by increasing the number of evaluation criteria (lane number, width and traffic signs, etc.) used in the study.

\section{Conclusions}

The most important areas in terms of urban transportation are intersections. Since the traffic density is higher in intersection areas than other road sections, negative factors such as traffic mobility, congestion and accidents are observed in these areas. Intersections need to be carefully analyzed in a scientific and technical framework. The aim of this study was to provide improvements for the corridor section, which is the most central part of Istanbul, taking into account various traffic performance criteria. In this context, MCDA and microsimulation method, which is an integrated approach for corridor analysis, were 
used. First of all, nine criteria that affect the intersection designs were determined utilizing literature, author and expert opinion. AHP method was preferred for weighting process of evaluation criteria. As a result of the weighing process, the most important criterion was C.6-Vehicle Safety. The least important criterion was observed as C.4-Stops. The traffic volume values were obtained by the counts. Considering these traffic volume values, the designs of the alternative corridors were performed by PTV VISSIM. Using the performance values of the evaluation criteria and expert opinions, the most suitable alternative corridor designs were performed by ranking process by TOPSIS. According to the process, the best corridor design was observed to be alternative corridor 5 . When compared to the performance values of the current and best alternative corridor, improvements of up to $80 \%$ for evaluation criteria are possible. As a result of these improvements, it is possible to achieve a more sustainable transportation and city. These improvements contribute to subjects such as economy, time, environment, and energy. Furthermore, if the most suitable corridor design analysis is carried out on a large scale, it can provide a partial solution to the various problems (environmental and noise pollution, waste of time, fuel consumption) caused by vehicles especially in metropolitan cities. In addition, sensitivity analysis was applied to the study to show that the results were sensitive according to the criteria weights.

Future studies can be performed using other MCDA methods as VlseKriterijuska Optimizacija I Komoromisno Resenje (VIKOR), Preference Ranking Organization Method for Enrichment of Evaluations (PROMETHEE) and Complex Proportional Assessment (COPRAS). Number of lanes, the width of lanes and traffic signs can be included in the study as technical criteria. Undertaking the suitability analysis of the locations of the intersections in the corridor with the help of Geographical Information Systems can be evaluated with VISSIM. Finally, the study area of the VISSIM-based MCDM method in other areas can be expanded.

Author Contributions: Conceptualization, K.D.A. and Ö.K.; methodology, K.D.A. and Ö.K.; software, K.D.A., Ö.K. and A.A.; validation, K.D.A., A.T., Ö.K. and A.A.; formal analysis, K.D.A. and Ö.K.; investigation, K.D.A. and Ö.K.; resources, K.D.A. and Ö.K.; data curation, K.D.A. and Ö.K.; writing—original draft preparation, K.D.A. and Ö.K.; writing—review and editing, K.D.A. and Ö.K.; visualization, K.D.A. and Ö.K.; supervision, A.T. and A.A. All authors have read and agreed to the published version of the manuscript.

Funding: This research received no external funding.

Institutional Review Board Statement: Not applicable.

Informed Consent Statement: Not applicable.

Data Availability Statement: Not applicable.

Acknowledgments: The traffic volume data used in the study were obtained from Istanbul Metropolitan Municipality. Relevant and more detailed data can be accessed from Istanbul Metropolitan Municipality. We would like to thank the Istanbul Metropolitan Municipality for their support.

Conflicts of Interest: The authors declare no conflict of interest.

\section{References}

1. Turkish Statistical Institute Number of Vehicles. 2018. Available online: http://www.tuik.gov.tr/PreIstatistikTablo.do?istab_id= 1581 (accessed on 19 April 2019).

2. General Directorate of Security (GDS) Traffic Accident and Audit Statistics-in Turkish. Available online: https://www.pa.edu.tr/ Upload/editor/files/Trafik_Kaza_ve_Denetim_İstatistikleri.pdf (accessed on 3 December 2020).

3. Posada, J.J.; González, C.; Farbiaz, V. A Policy on Geometric Design of Highways and Streets; AASHTO: Washington, DC, USA, 2015; ISBN 265571500.

4. Mandavilli, S.; Rys, M.J.; Russell, E.R. Environmental impact of modern roundabouts. Int. J. Ind. Ergon. 2008, 38, 135-142. [CrossRef]

5. Kwak, J.; Park, B.; Lee, J. Evaluating the impacts of urban corridor traffic signal optimization on vehicle emissions and fuel consumption. Transp. Plan. Technol. 2012, 35, 145-160. [CrossRef] 
6. Sun, D.; Zhang, L.; Chen, F. Comparative study on simulation performances of CORSIM and VISSIM for urban street network. Simul. Model. Pract. Theory 2013, 37, 18-29. [CrossRef]

7. Golbabaei, F.; Nejad, F.M.; Noory, A.R. A microscopic analysis of speed deviation impacts on lane-changing behavior. Transp. Plan. Technol. 2014, 37, 391-407. [CrossRef]

8. Chauhan, B.P.; Joshi, G.J.; Parida, P. Car following model for urban signalised intersection to estimate speed based vehicle exhaust emissions. Urban Clim. 2019, 29. [CrossRef]

9. Dimitrov, S.; Ceder, A.; Chowdhury, S.; Monot, M. Modeling the interaction between buses, passengers and cars on a bus route using a multi-agent system. Transp. Plan. Technol. 2017, 40, 592-610. [CrossRef]

10. Bayrak, O.U.; Abret, N.E. A multi-criteria decision for determining the appropriate junction design type: AHP approach with microsimulation. Fresenius Environ. Bull. 2019, 28, 7183-7195.

11. Lam, J.S.L.; Dai, J. A decision support system for port selection. Transp. Plan. Technol. 2012, 35, 509-524. [CrossRef]

12. Shiau, T.A. Evaluating transport infrastructure decisions under uncertainty. Transp. Plan. Technol. 2014, 37, 525-538. [CrossRef]

13. Kabit, M.R.B.; Charles, P.; Ferreira, L.; Kim, I. Modelling major traffic incident impacts and estimation of their associated costs. Transp. Plan. Technol. 2014, 37, 373-390. [CrossRef]

14. Saat, M.R.; Aguilar Serrano, J. Multicriteria high-speed rail route selection: Application to Malaysia's high-speed rail corridor prioritization. Transp. Plan. Technol. 2015, 38, 200-213. [CrossRef]

15. Du, Y.; Zhao, C.; Zhang, X.; Sun, L. Microscopic simulation evaluation method on access traffic operation. Simul. Model. Pract. Theory 2015, 53, 139-148. [CrossRef]

16. Sun, D.; Chen, S.; Zhang, C.; Shen, S. A bus route evaluation model based on GIS and super-efficient data envelopment analysis. Transp. Plan. Technol. 2016, 39, 407-423. [CrossRef]

17. Pilko, H.; Mandžuka, S.; Barić, D. Urban single-lane roundabouts: A new analytical approach using multi-criteria and simultaneous multi-objective optimization of geometry design, efficiency and safety. Transp. Res. Part C Emerg. Technol. 2017, 80, 257-271. [CrossRef]

18. Joo, S.; Lee, G.; Oh, C. A multi-criteria analysis framework including environmental and health impacts for evaluating traffic calming measures at the road network level. Int. J. Sustain. Transp. 2019, 13, 15-23. [CrossRef]

19. Demiral, A.C.; Köfteci, S. Analysis of intersection performance with package program: Antalya Muratpaşa Sampi intersection example. Int. J. Environ. Sci. Technol. 2019, 16, 5319-5324. [CrossRef]

20. Kaya, I.; Kahraman, C. A comparison of fuzzy multicriteria decision making methods for intelligent building assessment. J. Civ. Eng. Manag. 2014, 20, 59-69. [CrossRef]

21. Rashid, K.; Rehman, M.U.; de Brito, J.; Ghafoor, H. Multi-criteria optimization of recycled aggregate concrete mixes. J. Clean. Prod. 2020, 276, 124316. [CrossRef]

22. Comert, G. Effect of stop line detection in queue length estimation at traffic signals from probe vehicles data. Eur. J. Oper. Res. 2013, 226, 67-76. [CrossRef]

23. Yao, J.; Zhang, K.; Yang, Y.; Wang, J. Emergency vehicle route oriented signal coordinated control model with two-level programming. Soft Comput. 2018, 22, 4283-4294. [CrossRef]

24. Zheng, F.; Van Zuylen, H.; Liu, X. A methodological framework of travel time distribution estimation for urban signalized arterial roads. Transp. Sci. 2017, 51, 893-917. [CrossRef]

25. Stevanovic, A.; Stevanovic, J.; Zhang, K.; Batterman, S. Optimizing traffic control to reduce fuel consumption and vehicular emissions: Integrated approach with VISSIM, CMEM, and VISGAOST. Transp. Res. Rec. 2009, 105-113. [CrossRef]

26. Huang, Y.; Bird, R.; Bell, M. A comparative study of the emissions by road maintenance works and the disrupted traffic using life cycle assessment and micro-simulation. Transp. Res. Part D Transp. Environ. 2009, 14, 197-204. [CrossRef]

27. Stevanovic, A.; Stevanovic, J.; Kergaye, C. Optimization of traffic signal timings based on surrogate measures of safety. Transp. Res. Part C Emerg. Technol. 2013, 32, 159-178. [CrossRef]

28. Alemdar, K.D.; Kaya, Ö.; Çodur, M.Y. A GIS and microsimulation-based MCDA approach for evaluation of pedestrian crossings. Accid. Anal. Prev. 2020, 148. [CrossRef] [PubMed]

29. Mathew, T.V.; Radhakrishnan, P. Calibration of microsimulation models for nonlane-based heterogeneous traffic at signalized intersections. J. Urban Plan. Dev. 2010, 136, 59-66. [CrossRef]

30. Park, B.; Schneeberger, J.D. Microscopic Simulation Model Calibration and Validation: Case Study of Vissim Simulation Model for a Coordinated Actuated Signal System. Transp. Res. Rec. 2003, 185-192. [CrossRef]

31. Tianzi, C.; Shaochen, J.; Hongxu, Y. Comparative Study of VISSIM and SIDRA on Signalized Intersection. Procedia-Soc. Behav. Sci. 2013, 96, 2004-2010. [CrossRef]

32. Ishak, S.; Qi, Y.; Rayaprolu, P. Safety evaluation of joint and conventional lane merge configurations for freeway work zones. Traffic Inj. Prev. 2012, 13, 199-208. [CrossRef] [PubMed]

33. Moen, B.; Fitts, J.; Carter, D.; Ouyang, Y. A Comparison of the VISSIM Model to Other Widely Used Traffic Simulation and Analysis Programs. In Proceedings of the ITE 2000 Annual Meeting and Exhibit, Nashville, TN, USA, 6-9 August 2000; Transportation Research Board: Washington, DC, USA, 2000.

34. Ratrout, N.; Rahman, S. A comparative analysis of currently used microscopic and macroscopic traffic simulation software. Arab. J. Sci. Eng. 2009, 34, 121-133.

35. Saaty, T.L. A scaling method for priorities in hierarchical structures. J. Math. Psychol. 1977, 15, 234-281. [CrossRef] 
36. Chou, Y.C.; Hsu, Y.Y.; Yen, H.Y. Human resources for science and technology: Analyzing competitiveness using the analytic hierarchy process. Technol. Soc. 2008, 30, 141-153. [CrossRef]

37. Schweiger, G.; Gomes, C.; Engel, G.; Hafner, I.; Schoeggl, J.; Posch, A.; Nouidui, T. An empirical survey on co-simulation: Promising standards, challenges and research needs. Simul. Model. Pract. Theory 2019, 95, 148-163. [CrossRef]

38. Unutmaz Durmuşoğlu, Z.D. Assessment of techno-entrepreneurship projects by using Analytical Hierarchy Process (AHP). Technol. Soc. 2018, 54, 41-46. [CrossRef]

39. Durán, O.; Aguilo, J. Computer-aided machine-tool selection based on a Fuzzy-AHP approach. Expert. Syst. Appl. 2008, 34, 1787-1794. [CrossRef]

40. Ho, W. Integrated analytic hierarchy process and its applications-A literature review. Eur. J. Oper. Res. 2008, 186, 211-228. [CrossRef]

41. Liu, S.; Zhao, Q.; Wen, M.; Deng, L.; Dong, S.; Wang, C. Assessing the impact of hydroelectric project construction on the ecological integrity of the Nuozhadu Nature Reserve, southwest China. Stoch. Environ. Res. Risk Assess. 2013, 27, 1709-1718. [CrossRef]

42. Saaty, T.L. Decision making with the analytic hierarchy process. Int. J. Serv. Sci. 2008, 1, 83-98. [CrossRef]

43. Sennaroglu, B.; Varlik Celebi, G. A military airport location selection by AHP integrated PROMETHEE and VIKOR methods. Transp. Res. Part D Transp. Environ. 2018, 59, 160-173. [CrossRef]

44. Tzeng, G.H.; Huang, J.J. Multiple Attribute Decision Making: Methods and Applications; Taylor \& Francis: New York, NY, USA, 2011; ISBN 9781439861585.

45. Chen, P. Effects of normalization on the entropy-based TOPSIS method. Expert. Syst. Appl. 2019, 136, 33-41. [CrossRef]

46. National Research Council. HCM 2010; Transportation Research Board: Washington, DC, USA, 2010; ISBN 0-309-06681-6. 